\title{
The influence of sowing date and germination temperature on yield of spinach and chervil
}

\author{
J. E. Parlevliet * \\ Unilever Research Laboratory, Duiven, P.O. Box 7, Zevenaar, The Netherlands \\ Received 25 July, 1967
}

\begin{abstract}
Summary
Low temperatures during germination and in the young seedling stage induce an earlier flowering in spinach and chervil. This has important consequences for the yields, measured at a specified stage of development. Seed vernalization reduced yields considerably in both crops, especially at the later sowings. After germination at a higher temperature $\left(20^{\circ} \mathrm{C}\right)$ for 4 days, yields were considerably higher in both crops, this effect being strongest at early sowings for spinach and at late sowings for chervil.
\end{abstract}

\section{Introduction}

When a crop is sown in the late spring, higher temperatures occur during the early stages of its development. For crops adapted to temperate climates van Dobben (1962) observed that increased temperatures accelerated development more than growth, thus causing lower yields. If such a crop is also long day (LD) requiring for its development, such as spinach (Spinacia oleracea L.) and chervil (Anthriscus cerefolium Hoffm.) the yield will drop even more with later sowings (Parlevliet 1967a, b). The longer days to which the later sowings are exposed cause an extra acceleration of the development relative to growth.

For spinach and chervil, both 'temperate climate' crops, the practical results were only in partial agreement with this expectation. Experiments carried out at Duiven in 1963 and 1964 showed that the yield of spinach increases with later sowing until a maximum yield is reached for sowings in the first half of April. Still later sowings do indeed show a sharp drop in yield. Sowing date experiments in Northern Italy on 3 sites with 3 cultivars (cvs) indicated the same relationship between yield and sowing date; the optimal sowing date, however, was found to be about 2 weeks earlier (Mombelloni and de Letter, 1964). Similar trials with chervil did not show a yield decrease at all; yields steadily increased with later sowing.

The data of the above-mentioned experiments are shown in Fig. 1. All spinach cvs investigated have similar yield/sowing date curves, the optimum sowing date being earlier, the later the $\mathrm{cv}$ (Parlevliet, 1967a). In the figure the data of only one $\mathrm{cv}$ 'Nobel', are given. In chervil, too, the cvs behave similarly. Here the data of the 4 cvs could be averaged because the relationship between yield and sowing date was almost a linear one, within the date range tested.

* Present address : Pyrethrum Research Station, Molo, Kenya (East Africa). 
Fig. I Spinach, cv 'Nobel', and chervil yields in relation to sowing date in spring.

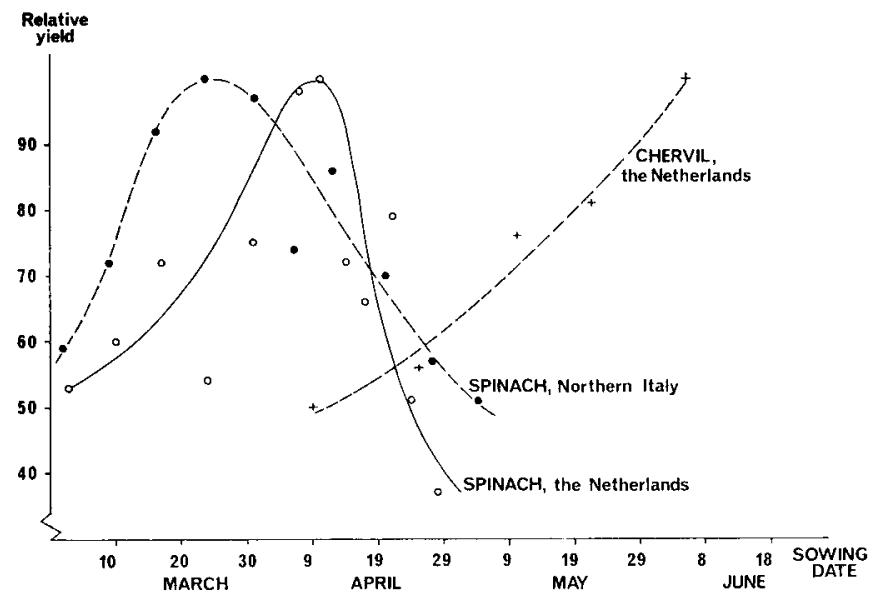

Vernalization during the germination stage results in earlier flowering in both crops, the effect in chervil being much stronger than in spinach. Due to the earlier flowering, yields might be reduced. It was therefore assumed that the initial higher yields of spinach and the consistently increasing yields of chervil with later sowing were due to a weakening of the vernalization, resulting from the higher temperatures. To test this assumption experiments with spinach and chervil were carried out in the spring of 1966 .

\section{Methods}

Spinach, cv 'Nobel' (supplier A. R. Zwaan), and chervil, cv 'Gewone' (supplier Gebr. Sluis), were sown on 3 dates in soil-blocks of $5 \times 5 \times 5 \mathrm{~cm}$, which were placed in the open air. The sowing dates were 9th March, to seccure natural vernalization (nV), 7th April, this being approximately the optimal sowing date for spinach in the Eastern part of Holland, and 9th May, to be fairly sure that in spinach no vernalization would occur. On respectively 23rd March, 18th April and 17th May these soilblocks were planted in the field, together with seeds germinated in similar blocks held at $20^{\circ} \mathrm{C}$ for 4 days (non-vernalized, -V) or at $5^{\circ} \mathrm{C}$ for 18 days (vernalized, $+\mathrm{V})$. The $-\mathrm{V}$ and $+\mathrm{V}$ treatments were also planted in a glasshouse on the abovementioned dates. From the first planting date onwards the temperature in the glasshouse was kept above $12^{\circ} \mathrm{C}$ to avoid possible vernalization in spinach. Each plot in the field or in the glasshouse consisted of a double-row of soil-blocks one meter long. The row distance was $0.50 \mathrm{~m}$. There were 4 replicates in the field and 2 in the glasshouse. Two to three weeks after emergence the plots were thinned to obtain equal plant densities. This resulted in about 30 plants per plot.

The crops were harvested at a stem length of $7 \mathrm{~cm}$ for spinach and $10 \mathrm{~cm}$ for chervil. Fresh and dry weight of the shoots, number of plants and average stem length were determined. 


\section{Results and discussion}

\section{Spinach}

The emergence of the $-\mathrm{V}, \mathrm{nV}$ and $+\mathrm{V}$ treatments occurred almost simultaneously for each sowing, the difference never exceeding 2 days. Table 1 shows the yield data. In the glasshouse the yields (fresh as well as dry weights) of the $-\mathrm{V}$ and $+\mathrm{V}$ treatments strongly decreased with later sowing. Since the temperature in the glasshouse was high enough to prevent vernalization after planting, these yield-drops must be ascribed to the combined effect of increasing temperatures and increasing daylengths, as discussed in the introduction. The average daily glasshouse temperatures between planting and harvesting for the 3 sowings indeed increased from 15 , to 19 and $23^{\circ} \mathrm{C}$ respectively. At each sowing " $+V$ " was earlier and yielded less than "- $V$ ", confirming that the acceleration of bolting by seed vernalization considerably reduces the yield.

In the field the situation is more complex because natural vernalization occurs, particularly at the earlier sowings. The $+\mathrm{V}$ treatments yielded less with later sowing, like they did in the glasshouse, though the effect was less pronounced. Since vernalization was optimal at all 3 sowings, the decrease in yield must also be attributed to the increasing temperature and daylength. As the daylength is identical in the field and the glasshouse, the much greater yield decrease with later sowing in the glasshouse must be attributed to the higher temperatures, suggesting that also under field conditions the increasing temperature is the major yield reducing factor in spinach when sown later in spring.

At the first sowing, $S_{1}$, in the first half of March, maximal vernalization occurs. Therefore the yield and earliness of " $n \mathrm{~V}$ " and " $+\mathrm{V}$ " are similar. At the third sowing, $S_{3}$, the "nV" and "- $V$ " yielded equally well and much better than " $+V$ ". Apparently the early May sowings are not vernalized at all. For the sowing date $S_{2}$, " $n \mathrm{~V}$ " takes an intermediate position between " $-\mathrm{V}$ " and " $+\mathrm{V}$ ", indicating that ver-

Table 1 Relative weights (yields) of spinach at a stem length of $7 \mathrm{~cm}$ in a glasshouse and in the field for three sowing dates. The seeds were germinated at about $20^{\circ} \mathrm{C}$ $(-V)$, in the field $(n V)$ or in a cold room at $5^{\circ} \mathrm{C}(+V)$.

\begin{tabular}{|c|c|c|c|c|c|}
\hline \multirow{2}{*}{$\begin{array}{l}\text { Sowing } \\
\text { date }\end{array}$} & \multicolumn{2}{|c|}{ Glasshouse } & \multicolumn{3}{|c|}{ Field } \\
\hline & $-V$ & $+V$ & $-V$ & $n V$ & $+V$ \\
\hline \multicolumn{6}{|c|}{ Relative fresh weights } \\
\hline $\mathbf{S}_{1}$ & 100 & 27 & 100 & 70 & 71 \\
\hline $\mathbf{S}_{2}$ & 50 & 20 & 112 & 83 & 64 \\
\hline $\mathbf{S}_{3}$ & 15 & 7 & 64 & 66 & 46 \\
\hline \multicolumn{6}{|c|}{ Relative dry weights } \\
\hline $\mathbf{S}_{1}$ & 100 & 28 & 100 & 78 & 77 \\
\hline $\mathbf{S}_{2}$ & 44 & 20 & 148 & 103 & 70 \\
\hline $\mathbf{S}_{3}$ & 13 & 8 & 70 & 77 & 48 \\
\hline \multicolumn{6}{|c|}{ Days from emergence to harvest (earliness) } \\
\hline $\mathbf{S}_{1}$ & 49 & 38 & 59 & 56 & 55 \\
\hline $\mathrm{S}_{2}$ & 33 & 24 & 48 & 44 & 38 \\
\hline$S_{3}$ & 27 & 23 & 31 & 30 & 27 \\
\hline
\end{tabular}


nalization in the optimal sowing period (5-15th April, see Fig. 1) is sub-maximal. The treatment of " $-V$ " consists of germination at $20^{\circ} \mathrm{C}$ for 4 days. The temperatures at the sowing dates $S_{1}$ and $S_{2}$ are sufficiently low to bring about vernalization. From the fact that in these cases " $-\mathrm{V}$ " yields better than " $\mathrm{nV}$ " and " $+\mathrm{V}$ ", we may draw the conclusion that the temperature has a profound, far-reaching influence, particularly during the first few days of germination.

It has now clearly been shown that the yield of spinach as a function of the sowing date is determined by two opposing tendencies. At later sowings the yield increases because of weaker vernalization; on the other hand, yield tends to decrease due to higher temperatures and longer daylengths. At intermediate sowing dates a maximum yield is obtained, as is apparent from Fig. 1 and Table 1.

\section{Chervil}

After seed vernalization, bolting and flowering occur rapidly in LD and not at all in short-day (SD). Without seed vernalization, flower formation is very late or completely inhibited (Parlevliet, 1967b). These facts explain the experimental yield/sowing date figures, given in Table 2. The emergence of " $-\mathrm{V}$ ", " $\mathrm{nV}$ " and " $+\mathrm{V}$ " occurred, as in spinach, almost simultaneously for each sowing, differences never exceeding 3 dayo.

In the glasshouse, the yields of "- $V$ " increase, whilst those of " $+V$ " decrease with later sowing. This decrease may again be attributed to the direct effect of increasing temperature and daylength, both stimulating bolting more than vegetative growth. The yield increase of "-V" with later sowing must therefore be due to another cause. Most likely this is due to a weakening of vernalization, resulting from the increasing temperature at, and just after, planting; this temperature increasing from $12^{\circ} \mathrm{C}$ at $\mathrm{S}_{1}$, to $16^{\circ} \mathrm{C}$ at $\mathrm{S}_{2}$ and to $20^{\circ} \mathrm{C}$ at $\mathrm{S}_{3}$. These are average day-time temperatures, the night temperatures being a few degrees lower. Because vernalization in

Table 2 Relative weights (yields) of chervil at a stem length of $10 \mathrm{~cm}$ in a glasshouse and in the field for three sowing dates. The seeds were germinated at about $20^{\circ} \mathrm{C}$ $(-V)$, in the field $(n V)$ or in a cold room at $5^{\circ} \mathrm{C}(+V)$.

\begin{tabular}{|c|c|c|c|c|c|}
\hline \multirow{2}{*}{$\begin{array}{l}\text { Sowing } \\
\text { date }\end{array}$} & \multicolumn{2}{|c|}{ Glasshouse } & \multicolumn{3}{|c|}{ Field } \\
\hline & $--V$ & $+V$ & $-V$ & $n V$ & $+V$ \\
\hline \multicolumn{6}{|c|}{ Relative fresh weights } \\
\hline $\mathbf{S}_{1}$ & 100 & 77 & 100 & 77 & 72 \\
\hline $\mathrm{S}_{2}$ & 324 & 65 & 147 & 88 & 86 \\
\hline $\mathrm{S}_{3}$ & $900 *$ & 44 & $>200$ & 112 & 53 \\
\hline \multicolumn{6}{|c|}{ Relative dry weights } \\
\hline $\mathbf{S}_{1}$ & 100 & 81 & 100 & 76 & 70 \\
\hline $\mathrm{S}_{2}$ & 327 & 64 & 164 & 99 & 97 \\
\hline $\mathbf{S}_{3}$ & $890 \%$ & 42 & $>256$ & 145 & 66 \\
\hline \multicolumn{6}{|c|}{ Days from emergence to harvest (earliness) } \\
\hline$S_{1}$ & 39 & 38 & 61 & 59 & 59 \\
\hline $\mathrm{S}_{2}$ & 44 & 28 & 48 & 43 & 42 \\
\hline $\mathrm{S}_{3}$ & 90 & 25 & 61 & 40 & 33 \\
\hline
\end{tabular}

* Cut 3 times on $5 / 7,3 / 8$ and $17 / 8$ 
chervil may occur at temperatures between 5 and $18^{\circ} \mathrm{C}$, some vernalization is to be expected at $S_{1}$ and at $S_{2}$. At $S_{1}$, natural vernalization of the $-V$ treatment was almost optimal as the earliness was only one day less than " $+V$ ". At $S_{2}$, vernalization was apparently much less; harvesting took place 16 days after " $+V$ ", resulting in a much greater yield. It took long before bolting occurred in the $S_{3}$ plants; vernalization apparently being sharply reduced. These results show that vernalization is the most important factor in the bolting behaviour of chervil.

For the field sowings the same trends are apparent in a moderated way. As the field temperatures increase more slowly than those in the glasshouse, the more slowly decreasing vernalization in the field gives less pronounced yield increases. At $S_{3}$ the $\mathrm{nV}$ trial took up an intermediate position between "- V" and " $+\mathrm{V}$ ". For spinach a similar intermediate position was found at $\mathbf{S}_{2}$. This agrees well with the experimental results, which showed that the upper limit of vernalizing temperatures was higher for chervil than for spinach (Parlevliet, 1967a, b).

The yield of chervil in relation to sowing date, when measured at a comparable development stage is obviously largely determined by decreasing vernalization at later sowing, this effect being more important than those of temperature and daylength. In both crops, 4 days of germination at about $20^{\circ} \mathrm{C}(-\mathrm{V})$ resulted in a considerable greater yield compared with germination in the field $(\mathrm{nV})$. This yield increase was highest at early sowings for spinach and at later sowings for chervil.

\section{References}

Dobben, W. H. van, 1962. Influence of temperature and light conditions on dry matter distribution, development rate and yield in arable crops. Neth. J. Agric. Sc. $10: 377-389$.

Mombelloni, S. and Letter, J. B. de, 1964. Personal communication.

Parlevliet, J. E., 1967a. Influence of external factors on the growth and development of spinach cultivars (Spinacia oleracea L.). Mededel. Landbouwhogeschool Wageningen, 67-2: 75 pp.

Parlevliet, J. E., $1967 \mathrm{~b}$. Temperature and daylength requirements in flower initiation of chervil. (Anthriscus cerefolium Hoffm.). Zeitschr. für Pflanzenphys. (in press) 